\title{
Daño del ADN como marcador potencial en el seguimiento clínico de pacientes femeninas con cáncer tratado
}

\author{
DNA damage as a potential marker in the clinical follow-up of female patients with treated \\ cancer
}

Judith Beatriz Pupo-Balboa ${ }^{\mathrm{a}}$, Martha Sonia Robaina-Castellanos ${ }^{\mathrm{b}}$ (D), Reinaldo Gutiérrez-Gutiérrez ${ }^{\mathrm{a}}$ (D), Anamarys Pandolfi-Blanco ${ }^{\mathrm{a}}$ (D), Lucía Fariñas-Rodríguez ${ }^{\mathrm{a}}$ (D)

\begin{abstract}
Objective: To identify individual differences in the basal damage (DB) of peripheral leukocyte DNA from women with cancer in remission. Methods: Cross-sectional analytical study in which 24 women with cancer in remission from different locations and 24 supposedly healthy women participated. The alkaline comet assay and the neutral variant were used to determine single-stranded breaks (DB-A), and double-stranded DNA breaks (DB-N), respectively. Results: Although there were no differences between the mean values of DNA damage in patients and controls ( $D B-N: p=0.43$ and $D B-A: p=0.13$ ), $41.6 \%$ of the patients presented an increase of one type or another of DNA breaks, with respect to the corresponding cut-off points of the control women. DB-N was correlated with increasing age $(r 2=0.1833 ; r=0.4281 ; p=0.036)$ in the patients. DB-A was elevated in those who had received anticancer combination therapy $(p=0.024)$ and in those who were undergoing treatment with tamoxifen $(p=0.033)$; while it was decreased in those that consumed antioxidants $(p=0.006)$ and in those that combined tamoxifen and antioxidants $(p=0.020)$. Conclusions: Individual differences were identified in both types of DNA strand breaks that are of medical interest in the studied patients. Baseline DNA damage determined by comet assay is a potential tool in the clinical follow-up of cancer patients in remission.
\end{abstract}

Keywords: Cancer, alkaline comet assay, neutral comet assay, DNA damage.

\section{Resumen}

Objetivo: Identificar diferencias individuales en el daño basal (DB) del ADN de leucocitos periféricos de mujeres con cáncer en remisión. Métodos: Estudio analítico de corte transversal en el que participaron 24 mujeres con cáncer en remisión de diferentes localizaciones y 24 mujeres supuestamente sanas. Se utilizó el ensayo cometa alcalino y la variante neutral para determinar roturas de simple hebra (DB-A), y roturas de doble hebra del ADN (DB-N), respectivamente. Resultados: Aunque no hubo diferencias entre los valores medios del daño del ADN de pacientes y controles (DB-N: $p=0,43$ y DB-A: $p=0,13)$, el $41,6 \%$ de las pacientes presentó aumento de un tipo u otro de roturas del ADN, respecto a los correspondientes puntos de corte de las mujeres controles. El DB-N estuvo correlacionado con el incremento de la edad $(r 2=0,1833 ; r=0,4281 ; p=0,036)$ en las pacientes. El DB-A estuvo elevado en aquellas que habían recibido politerapia anticáncer $(p=0,024)$ y en las que estaban realizando tratamiento con tamoxifeno $(p=0,033)$; mientras estuvo disminuido en las que consumieron antioxidantes $(p=0,006)$ y en las que combinaron tamoxifeno y antioxidantes $(p=0,020)$. Conclusiones: Se identificaron diferencias individuales en ambos tipos de roturas de hebra del ADN que resultan de interés médico en las pacientes estudiadas. El daño basal del ADN determinado por ensayo cometa es una herramienta potencial en el seguimiento clínico de pacientes con cáncer en remisión.

Palabras clave: Cáncer, Ensayo cometa alcalino, Ensayo cometa neutral, Daño del ADN.

a. Laboratorio de Estrés Oxidativo. Centro Nacional de Genética Médica. Dirección: Ave. 31 Esq.146 No 3102, Reparto Cubanacán, CP 11400 , La Habana. Cuba.

b. Servicio de Ontogenética. Instituto Nacional de Oncología y Radiobiología. Dirección: Calle 29 esquina F, Vedado, Plaza de la Revolución, CP 10400, La Habana, Cuba.

Autor para correspondencia: Judith Pupo-Balboa, MD Correo electrónico: judith.pupo@infomed.sld.cu 


\section{Introducción}

El cáncer es una de las enfermedades no trasmisibles que afecta seriamente a la salud humana en la actualidad $(1,2)$. Se plantea que presenta etiología multifactorial donde se integran factores de riesgo del macroambiente, individuales y biológicos (3). Entre los factores biológicos, el daño incrementado del ADN y una reparación ineficiente se han descrito como eventos moleculares importantes, al producir inestabilidad genómica que puede conducir a mutaciones y carcinogénesis $(4,5)$.

La inestabilidad genómica en el cáncer está asociada a mutaciones en genes que participan como sensores o reparadores del daño del ADN. Por ejemplo, mutaciones germinales en genes supresores tumorales como los genes BRCA1 (gen 1 de susceptibilidad al cáncer de mama) y BRCA2 (gen 2 de susceptibilidad al cáncer de mama) imputan un riesgo incrementado para el cáncer de mama y ovario, contribuyendo al $20 \%$ de los cánceres familiares en estas localizaciones. En menor proporción, se han asociado a cáncer de otras localizaciones como próstata, colon, recto, páncreas y estómago (6). Mutaciones en otros genes, como el gen supresor tumoral Rb1 (gen 1 de Retinoblastoma), un regulador del ciclo celular, están presentes en la mayoría de los cánceres humanos. Específicamente, mutaciones germinales en este gen causan el tumor de la infancia retinoblastoma y atribuyen un riesgo incrementado para otros tipos de cáncer como el osteosarcoma (7).

Por otra parte, los tratamientos utilizados para el cáncer, como la quimioterapia y la radioterapia, no son específicos y provocan diferentes tipos de daño del ADN, tanto en las células tumorales como en los tejidos normales. Producen daño directo como roturas de simple y doble hebra, bases modificadas y entrecruzamientos, o daño indirecto a través de la formación de radicales libres. Esto determina que exista un riesgo incrementado de desarrollar cáncer secundario, por lo que resulta importante realizar un continuo biomonitoreo a los pacientes que han recibido tratamiento con estos agentes $(8,9)$.

En correspondencia, se han utilizado varios biomarcadores para evaluar el riesgo potencial de desarrollar cáncer secundario, entre los que se encuentra la cuantificación directa del daño del ADN por ensayo cometa (10). El ensayo cometa o electroforesis en gel de células individuales es una técnica simple y sensible que permite cuantificar el daño y la reparación del ADN. Brevemente, las células son embebidas en geles de agarosa de bajo punto de fusión sobre láminas portaobjetos; posteriormente, son lisadas y sometidas a electroforesis. Bajo el campo eléctrico, el ADN fragmentado migra desde el núcleo hacia el ánodo, y se forma el patrón de migración que recuerda a un cometa. Una mayor migración conduce a un mayor contenido de ADN en la cola, que se corresponde con un mayor nivel de daño. El método, en su versión alcalina, utiliza condiciones desnaturalizantes y permite cuantificar roturas de simple hebra, sitios lábiles al álcali, y roturas de doble hebra del ADN que representan menos del $5 \%$ del daño total. La versión neutra del ensayo utiliza condiciones no desnaturalizantes y permite determinar más específicamente rompimientos dobles $(4,10)$. En efecto, el estudio de roturas de simple y doble hebra del ADN se ha descrito en pacientes con cáncer, mediante este ensayo $(11,12)$. Las roturas de simple hebra del ADN ocurren más comúnmente que las de doble hebra. Estas últimas, aunque menos frecuentes, presentan mayor significado biológico porque de no ser reparadas adecuadamente podrían conducir a cambios importantes como la muerte, la senescencia - la transformación celulares. Son consideradas altamente citotóxicas. Ambos tipos de roturas pueden ser inducidas tanto endógenamente por los procesos metabólicos que llevan a la formación de radicales libres, como por fuentes exógenas, como las radiaciones ionizantes $(5,11,12)$. La cuantificación de las roturas basales del ADN, mediante ensayo cometa en pacientes con cáncer, se ha reportado recientemente con un valor pronóstico potencial en el seguimiento de este tipo de pacientes $(13,14)$.

Como parte de los protocolos estándares establecidos para el diagnóstico, tratamiento y prevención del cáncer en el Instituto Nacional de Oncología y Radiobiología de Cuba, se realiza el seguimiento clínico a largo plazo de los pacientes con cáncer después de haber recibido tratamiento antineoplásico. Un grupo de pacientes femeninas, en seguimiento clínico con diferentes tipos de cáncer en remisión, fueron enroladas en el presente estudio con el objetivo de determinar los niveles basales de daño del ADN mediante las dos variantes del ensayo cometa, e identificar diferencias individuales de potencial importancia clínica. 


\section{Materiales y métodos}

Se realizó una investigación observacional analítica transversal en el laboratorio de Estrés Oxidativo, del Centro Nacional de Genética Médica, en el periodo de 2016 a 2017, que fue aprobada por el Comité de Ética Médica y de la Investigación de la institución, en la que se respetaron las normas éticas establecidas en la Declaración de Helsinki.

Sujetos de experimentación. La muestra estuvo constituida por mujeres con cáncer en remisión de diferentes localizaciones, atendidas en la consulta de oncogenética del Instituto Nacional de Oncología y Radiobiología de Cuba, que estuvieran de acuerdo en participar en el estudio. Participaron en total 25 pacientes femeninas con cáncer en diferentes localizaciones (Tabla 1). El promedio de edad de las pacientes fue de 42,64+17,1 años en un rango de 17 a 71 años. Los tipos de cáncer incluyeron carcinoma embrionario de glándulas suprarrenales (CEGS/1), retinoblastoma bilateral $(\mathrm{Rb}-\mathrm{B} / 1)$, retinoblastoma unilateral $(\mathrm{Rb}-\mathrm{U} / 1)$, neuroblastoma $(\mathrm{Nb} / 2)$, tumor de Wilms (TW/1), linfoma linfoblástico no Hodking $(\mathrm{LLNH} / 1)$, melanoma $(M / 1)$, cáncer de mama $(C M / 14)$ y cáncer ginecológico (CG/3). De todas las pacientes, 16 presentaron antecedentes familiares de cáncer (APF-C) en diferentes localizaciones. El tratamiento recibido incluyó resección quirúrgica, quimioterapia (QTP), radioterapia (RTP), inmunoterapia y/o tratamiento antiestrogénico. En el caso de este último, 13 pacientes con CM estaban recibiendo tratamiento con tamoxifeno. El periodo de remisión varió entre dos a tres meses después de terminado el tratamiento, hasta dos, cuatro, cinco y 11 años. Seis pacientes habían consumido suplementos antioxidantes durante seis meses previos al estudio; cinco consumieron multivitaminas, una tableta diaria (tiamina 2,5 mg; riboflavina 1,6 mg; nicotinamida $20 \mathrm{mg}$; ácido fólico 0,25 mg; piridoxina $2 \mathrm{mg}$; cianocobalamina $0,06 \mathrm{mg}$; retinol $50 \mathrm{U}$ ), y una consumió omega $3,500 \mathrm{mg}$ una vez por día. De las 25 pacientes, 24 participaron en el análisis comparativo con un grupo de control de mujeres aparentemente sanas. La paciente restante (43 años) con CM extirpado quirúrgicamente, había recibido la primera sesión de quimioterapia en el momento de realizar la investigación, y se consideró como control positivo de valores elevados de daño del ADN. El grupo de control estuvo constituido por 24 mujeres supuestamente sanas, con un promedio de edad de $38,1 \pm 12,5$ años en un rango de 15 a 62 años, que aportaron su sangre voluntariamente. Para su selección, se realizó una pesquisa activa que incluyó a mujeres acompañantes no relacionadas filialmente con las pacientes y a mujeres procedentes de la institución ejecutora de la investigación, que estuvieran interesadas en participar en la investigación. Ninguna de las pacientes y mujeres controles fueron fumadoras ni tuvieron como hábito el consumo de alcohol, no presentaron infecciones agudas ni exposición a radiaciones ionizantes en los 30 días previos a la extracción de sangre. Se excluyeron condiciones como embarazo, lactancia o enfermedades crónicas inflamatorias o metabólicas descompensadas. Todas las participantes fueron informadas sobre la investigación y aportaron su consentimiento informado.

En los dos grupos se determinó el daño basal del ADN mediante el ensayo cometa simple en sus dos variantes, alcalino y neutral. Los valores obtenidos fueron comparados entre los grupos mediante pruebas estadísticas, y además se analizaron las diferencias individuales observadas en las pacientes respecto a los puntos cortes de las mujeres controles. De acuerdo con la distribución de la edad en la muestra, las pacientes se agruparon en $\leq 25$ años y > 25 años. Particularmente, se analizó el daño del ADN en las pacientes conforme a la edad, al tratamiento antineoplásico recibido, la presencia de antecedentes patológicos de cáncer, el tiempo de remisión, el consumo de suplementos antioxidantes y el tratamiento con tamoxifeno.

Aislamiento de leucocitos. Se partió de $3 \mathrm{~mL}$ de sangre total heparinizada que fueron procesados antes de las 4 horas de extraídos. El aislamiento de las células se realizó por gradiente de centrifugación con ficoll Histopaque-1077 (Sigma), según el procedimiento referido por el grupo de trabajo (15). Brevemente, las muestras de sangre se extrajeron por punción venosa periférica a cargo de personal de laboratorio clínico, se transportaron refrigeradas, protegidas de la luz y codificadas, antes de las 3 horas de obtenidas. Las células se obtuvieron por centrifugación a 2200 rpm con Histopaque 1077 durante 30 minutos (Centrífuga Eppendorf 5415 R). La capa de la interfase se colectó con micropipeta y se realizaron 3 lavados de 10 minutos con tampón PBS frío en iguales condiciones de centrifugación. El sedimento de células se resuspendió en tampón PBS frío (Millipore) con una concentración aproximada de $1 \times 105^{5}$ células $/ \mathrm{mL}$. Se determinó la supervivencia celular con azul Trypan (Sigma), que fue del 95\%. 
Ensayo cometa. Se realizaron las dos variantes del ensayo cometa simple: la variante alcalina se desarrolló según Collins y colaboradores para determinar roturas de simple hebra del ADN (16). Brevemente, los leucocitos aislados se mezclaron con agarosa de bajo punto de fusión al $0,5 \%$ y se extendieron sobre duplicados de láminas portaobjetos cubiertas previamente con agarosa regular al $0,75 \%$.
Se cubrieron con cubreobjetos y se colocaron a $4^{\circ} \mathrm{C}$ durante 5 minutos. A continuación, se sumergieron en solución de lisis toda la noche a $4^{\circ} \mathrm{C}$ después de retirar los cubreobjetos. Al día siguiente, se realizó el desenrollamiento del ADN en tampón de $\mathrm{pH}>13$ ( $300 \mathrm{mM} \mathrm{NaOH} / 1 \mathrm{mM}$ EDTA) durante 25 minutos a $4^{\circ} \mathrm{C}$. Seguidamente, se efectuó la electroforesis en este mismo tampón a $25 \mathrm{~V}, 300 \mathrm{~mA}$.

Tabla 1. Características clínicas de las pacientes

\begin{tabular}{|c|c|c|c|c|c|c|c|c|}
\hline \multirow{2}{*}{$\begin{array}{l}\text { Localización } \\
\text { del cáncer }\end{array}$} & \multirow{2}{*}{\multicolumn{2}{|c|}{ Edad }} & \multirow{2}{*}{ APF cáncer } & \multicolumn{3}{|c|}{ Tratamiento antineoplásico } & \multirow{2}{*}{$\begin{array}{l}\text { Tiempo de } \\
\text { remisión }\end{array}$} & \multirow{2}{*}{$\begin{array}{l}\text { Suplementos } \\
\text { antioxidantes }\end{array}$} \\
\hline & & & & QTP & RTP & Otro & & \\
\hline CEGS & \multirow{7}{*}{$\begin{array}{l}\leq 25 \\
\text { años }\end{array}$} & 17 & $\begin{array}{l}\text { Diferentes localizaciones } \\
\text { (II grado) }\end{array}$ & - & - & $\begin{array}{l}\text { Terapia } \\
\text { Sustitutiva }\end{array}$ & 1 año & - \\
\hline $\mathrm{Rb}-\mathrm{B}$ & & 18 & $\begin{array}{l}\text { RB Bilateral (I grado) } \\
\text { Otras localizaciones (II grado) }\end{array}$ & - & - & Crioterapia & 4 años & - \\
\hline $\mathrm{Rb}-\mathrm{U}$ & & 19 & $\begin{array}{c}\text { Diferentes localizaciones } \\
\text { (III grado) }\end{array}$ & QTP? & RTP & - & 1 año & - \\
\hline \multirow{2}{*}{$\mathrm{Nb}$} & & 19 & - & QTP? & RTP & - & 1 año & Multivitaminas \\
\hline & & 20 & - & QTP? & - & & 1 año & - \\
\hline TW & & 21 & - & QTP? & RTP & - & 1 año & - \\
\hline LLNH & & 24 & - & QTP? & RTP & - & 1 año & - \\
\hline M & & 35 & - & QTP? & - & & 1 año & - \\
\hline \multirow{14}{*}{$C M$} & \multirow{14}{*}{$\begin{array}{l}>25 \\
\text { años }\end{array}$} & 39 & $\begin{array}{l}\text { Mama (I y II grado) y otras } \\
\text { localizaciones (II grado) }\end{array}$ & A, C, T & RTP & Tamoxifeno & 2 meses & - \\
\hline & & 43 & $\begin{array}{l}\text { Mama y otras localizaciones } \\
\text { (I y II grado) }\end{array}$ & $\begin{array}{l}\text { A, C (1 ra } \\
\text { sesión)* }\end{array}$ & - & - & Actual & - \\
\hline & & 44 & Mama y otras localizaciones & $\mathrm{A}, \mathrm{C}, \mathrm{T}$ & RTP & Tamoxifeno & 1 año & - \\
\hline & & 46 & - & $A, C, T$ & - & Tamoxifeno & 5 años & - \\
\hline & & 46 & - & $\mathrm{A}, \mathrm{C}, \mathrm{T}$ & - & Tamoxifeno & 1 año & Omega 3 \\
\hline & & 47 & $\begin{array}{c}\text { Mama y otras localizaciones } \\
\text { (I y II grado) }\end{array}$ & A, C, T & RTP & Tamoxifeno & 1 año & Multivitaminas \\
\hline & & 48 & $\begin{array}{l}\text { Mama y otras localizaciones } \\
\text { (II grado) }\end{array}$ & - & - & $\begin{array}{l}\text { Herseptin y } \\
\text { tamoxifeno }\end{array}$ & 2 años & - \\
\hline & & 56 & - & $\mathrm{A}, \mathrm{C}, \mathrm{T}$ & RTP & Tamoxifeno & 1 año & - \\
\hline & & 59 & Mama y otras localizaciones & $\mathrm{A}, \mathrm{C}, \mathrm{T}$ & RTP & Tamoxifeno & 1 año & - \\
\hline & & 59 & $\begin{array}{l}\text { Mama y otras localizaciones } \\
\text { (I grado) }\end{array}$ & $\mathrm{A}, \mathrm{C}, \mathrm{T}$ & - & Tamoxifeno & 11 años & Multivitaminas \\
\hline & & 60 & $\begin{array}{l}\text { Mama (I grado) y otras } \\
\text { localizaciones (II grado) }\end{array}$ & A, C, T & RTP & Tamoxifeno & 2 meses & - \\
\hline & & 61 & Mama y otras localizaciones & $\mathrm{A}, \mathrm{C}, \mathrm{T}$ & RTP & Tamoxifeno & 1 año & - \\
\hline & & 64 & $\begin{array}{l}\text { Mama (I grado) y otras } \\
\text { localizaciones } \\
\text { (I y II grado) }\end{array}$ & - & RTP. & Tamoxifeno & 1 año & Multivitaminas \\
\hline & & 71 & - & $\mathrm{A}, \mathrm{C}, \mathrm{T}$ & RTP & Tamoxifeno & 1 año & - \\
\hline \multirow{3}{*}{ CG } & & 33 & $\begin{array}{l}\text { Diferentes localizaciones } \\
\text { (I y II grado) }\end{array}$ & $P$ & RTP & - & 3 meses & - \\
\hline & & 55 & $\begin{array}{l}\text { Cervicouterino y otras } \\
\text { localizaciones } \\
\text { (I y || grado) }\end{array}$ & - & - & - & 1 año & Multivitaminas \\
\hline & & 62 & $\begin{array}{l}\text { Diferentes localizaciones } \\
\text { (I y II grado) }\end{array}$ & $A, C, P$ & - & - & 1 año & - \\
\hline
\end{tabular}

Leyenda: CEGS: Carcinoma embrionario de Glándulas Suprarrenales; Rb: Retinoblastoma; Nb: Neuroblastoma; TW: Tumor de Wilms; LLNH: Linfoma Linfoblástico No Hodking; M: Melanoma; CM: Cáncer de mama; CG: Cáncer Ginecológico; APF: antecedentes patológicos familiares; QTP?: no se obtuvo el dato de la quimioterapia realizada; RTP: radioterapia; * Paciente con CM que fue control positivo de daño elevado del ADN por exposición a QTP. A: adriamicina; C: ciclofosfamida; T: taxol; P: cisplatino 
durante 25 minutos a $4^{\circ} \mathrm{C}$ (Fuente eléctrica Cenic, Cuba). La neutralización se realizó con tampón frío $0.4 \mathrm{M}$ Tris, $\mathrm{pH}$ 7.5. La variante neutral del ensayo cometa se utilizó para determinar los niveles endógenos de roturas de doble hebra del ADN en condiciones de $\mathrm{pH}$ neutro. Se realizó de manera similar a la variante alcalina, con la diferencia de que se utilizó tampón TBE (Tris-borato-EDTA, pH $8,3)$ para equilibrar los geles durante 25 minutos y realizar la electroforesis en estas condiciones de $\mathrm{pH}$ neutro por otros 25 minutos (17).

Cuantificación del daño en el ADN. En el ensayo cometa alcalino, el daño del ADN se cuantificó en UA (unidades arbitrarias), acorde con 5 niveles $(0,1,2$, 3 y 4), de menor a mayor daño (16). En la variante neutral del ensayo se utilizaron 4 niveles de daño $(1,2,3$ y 4). (15). Los núcleos teñidos con nitrato de plata se observaron al microscopio óptico de campo claro a 400x. Se visualizaron 100 núcleos por lámina y se observaron 200 núcleos por cada individuo (16). Para calcular el daño se multiplica el número de cometas observados por la clasificación de los niveles de daño y se suman los valores obtenidos en cada gel para cada nivel (16), según las fórmulas:

Cometa alcalino:

$U A=n 0(0)+n 1(1)+n 2(2)+n 3(3)+n 4(4)$

Cometa neutral:

$\mathrm{UA}=\mathrm{n} 1(1)+\mathrm{n} 2(2)+\mathrm{n} 3(3)+\mathrm{n} 4(4)$

Donde, $\mathrm{n}$ es el número de células en el nivel de daño. El valor de las UA cuantificadas en cada lámina se promedió con su réplica y el valor final se utilizó en los análisis de los resultados.

Análisis estadístico. Se aplicó la estadística descriptiva y se determinó la normalidad de los datos. Los valores del ensayo cometa se expresaron como la media de las UA cuantificadas \pm error típico de la media (ETM). El daño del ADN de los controles se categorizó en cuartiles (18). El tercer cuartil (75\%) se utilizó como punto de corte, los niveles de daño por encima de este valor se consideraron aumentados en las pacientes, lo que permitió identificar diferencias individuales. Se determinó el estadígrafo $U$ de Mann Whitney para comparar dos grupos y el Kruskal-Wallis ANOVA para la comparación de múltiples grupos; se consideró una $p<0,05$ como significación estadística. Se utilizó el paquete estadístico Statistica 7.

\section{Resultados}

\section{Daño basal del ADN en las pacientes por grupo de edades}

Los niveles medios de roturas de simple y doble hebra del total de las pacientes fueron mayores (Tabla 2A), comparados con las mujeres controles, aunque sin significación estadística. La comparación entre pacientes y controles por grupos de edades de mayores de 25 años y las menores de esta edad, igualmente, no mostró diferencias, (Tabla 2B y 2C).

Al comparar las pacientes con base en estos grupos de edades se obtuvieron diferencias significativas en el daño basal por roturas de doble hebra (Tabla 2D, columna de Pacientes). Un análisis de regresión lineal en este grupo indicó correlación entre este tipo de daño y la edad, $\left(r^{2}=0,1833 ; r=0,4281\right.$; $p=0,036)$; mientras que para el daño por roturas de simple hebra no se encontró ninguna relación con la edad $\left(r^{2}=0,0581 ; r=-0,2411 ; p=0,256\right)$. Sin embargo, al comparar a las mujeres controles por grupo de edad no hubo diferencias (Tabla 2D, columna de Controles). La regresión lineal indicó que no hubo correlación entre la edad y el daño del ADN por ninguna de las variantes del ensayo (DB$\mathrm{N}: \mathrm{r}^{2}=0,0930 ; r=-0,3050 ; \mathrm{p}=0,147 ; \mathrm{DB}-\mathrm{N}: \mathrm{r}^{2}=$ $0,0112 ; r=-0,1057 ; p=0,622)$. Razonablemente, la diferencia entre edades fue significativa para ambos grupos $(p=0,000)$.

\section{Daño basal del ADN en las pacientes según la presencia de APF-C, el tratamiento antineoplásico recibido y el tiempo de remisión}

Se realizó el análisis de las pacientes agrupadas de acuerdo con la presencia de APF-C, el tratamiento antineoplásico recibido y el tiempo de remisión (Figura 1). El análisis comparativo de los diferentes grupos respecto a las mujeres controles no mostró diferencias significativas para los dos tipos de roturas del ADN, excepto en las pacientes politratadas (QTP + RTP) (Figura 1A, Grupo 3), que exhibieron un DB-A aumentado $(p=0,024)$; mientras que las pacientes que realizaron monoterapia (QTP o RTP) (Figura 1B, Grupo 4) presentaron valores medios del DB-N 
Tabla 2. Valores medios del DB-N y el DB-A del ADN en las pacientes y las mujeres controles. Análisis por grupos de edad de menores y mayores de 25 años. Puntos de corte de las mujeres controles

\begin{tabular}{|c|c|c|c|c|c|c|}
\hline & $\begin{array}{c}\text { Daño del ADN } \\
\text { según grupos de } \\
\text { edad }\end{array}$ & Pacientes & p & Controles & $\mathrm{p}$ & $\begin{array}{c}\text { Puntos de } \\
\text { corte: } 3 e r \\
\text { cuartil (75\%) }\end{array}$ \\
\hline \multirow[t]{4}{*}{ A } & Total & $N=24$ & - & $N=24$ & - & - \\
\hline & Edad Media & $42,62 \pm 17,5$ & - & $37,91 \pm 12,7$ & 0,32 & - \\
\hline & DB-N & $135 \pm 3$ & - & $128 \pm 3$ & 0,43 & 137,75 \\
\hline & DB-A & $31,89 \pm 2,4^{*}$ & - & $24,35 \pm 2,4$ & 0,13 & 30 \\
\hline \multirow[t]{4}{*}{ B } & > 25 años & $N=17$ & - & $N=17$ & - & - \\
\hline & Edad Media & $52 \pm 10,8$ & - & $45 \pm 6,3$ & 0,06 & - \\
\hline & $\mathrm{DB}-\mathrm{N}$ & $144,4 \pm 5,7^{* *}$ & - & $129 \pm 3,6$ & 0,10 & 135 \\
\hline & DB-A & $30,26 \pm 4,4^{*}$ & - & $22,7 \pm 2,9$ & 0,27 & 27,5 \\
\hline \multirow[t]{4}{*}{ C } & $\leq 25$ años & $N=7$ & - & $N=7$ & - & \\
\hline & Edad Media & $19,71 \pm 2,3$ & - & $20,6 \pm 1,7$ & 0,33 & - \\
\hline & DB-N & $117,21 \pm 2,4$ & - & $125,71 \pm 4$ & 0,34 & 138 \\
\hline & DB-A & $35,85 \pm 2,3^{*}$ & - & $28,3 \pm 5,8$ & 0,22 & 34 \\
\hline \multirow[t]{4}{*}{ D } & $\leq 25$ vs $>25$ & & - & & - & - \\
\hline & Edad Media & $19,71 \pm 2,3$ vs $52 \pm 10,8$ & 0,000 & $20,6 \pm 1,7$ vs $45 \pm 6,3$ & 0,000 & - \\
\hline & DB-N & $117,21 \pm 2,4$ vs $144,4 \pm 5,7$ & 0,009 & $125,71 \pm 4$ vs $129 \pm 3,6$ & 0,679 & - \\
\hline & DB-A & $35,85 \pm 2,3$ vs $30,26 \pm 4,4$ & 0,182 & $28,3 \pm 5,8$ vs $22,7 \pm 2,9$ & 0,182 & - \\
\hline
\end{tabular}

Leyenda: A: comparación entre el total de pacientes y el total de controles. B: comparación entre pacientes y controles mayores de 25 años. C: comparación entre pacientes y controles menores de 25 años; D: comparación entre grupo de pacientes mayores y menores de 25 años, y entre grupos de controles mayores y menores de 25 años. DB-A: daño basal del ADN determinado por ensayo cometa alcalino en unidades arbitrarias, que presenta las roturas de simple hebra del ADN; DB-N: daño basal del ADN determinado por ensayo cometa neutral en unidades arbitrarias, que representa las roturas de doble hebra; $\mathrm{p}<0,05$, prueba $U$ de Mann-Whitney.

* Valor por encima del tercer cuartil del daño por roturas de simple hebra de las mujeres controles

** Valor por encima del tercer cuartil del daño por roturas de doble hebra de las mujeres controles

cercanos a la significación estadística $(p=0,082)$. No obstante, la media del daño por roturas de simple hebra del ADN de las pacientes con APF-C (Figura 1A, Grupo 1), las pacientes con tiempo de remisión de 1 año (Figura $1 \mathrm{~A}$, Grupo 6) y las pacientes con tiempo de remisión < 1 año (Figura 1A, Grupo 7) se observó elevada, al tener en cuenta el punto de corte de las mujeres controles. Similarmente, el daño por roturas de doble hebra del $A D N$ estuvo incrementado en las pacientes sin APF-C (Figura 1B, Grupo 2) y en las pacientes con tiempo de remisión $>1$ año (Figura $1 \mathrm{~B}$, Grupo 8), en relación con el punto de corte de las mujeres controles. De todas las pacientes, solo las que no recibieron terapia anticáncer del tipo QTP o RTP (Figura 1, A y B, Grupo 5) tuvieron valores normales en ambos tipos de daño del ADN. 
A)

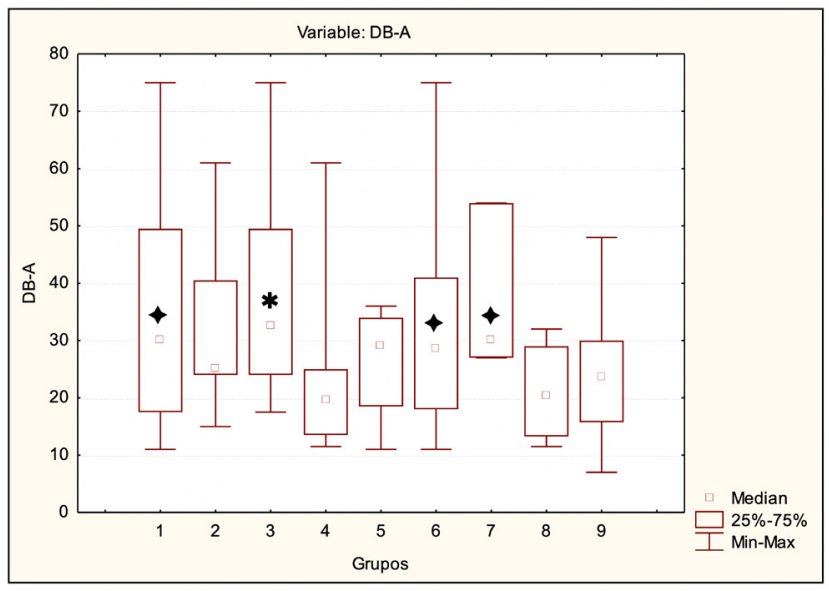

B)

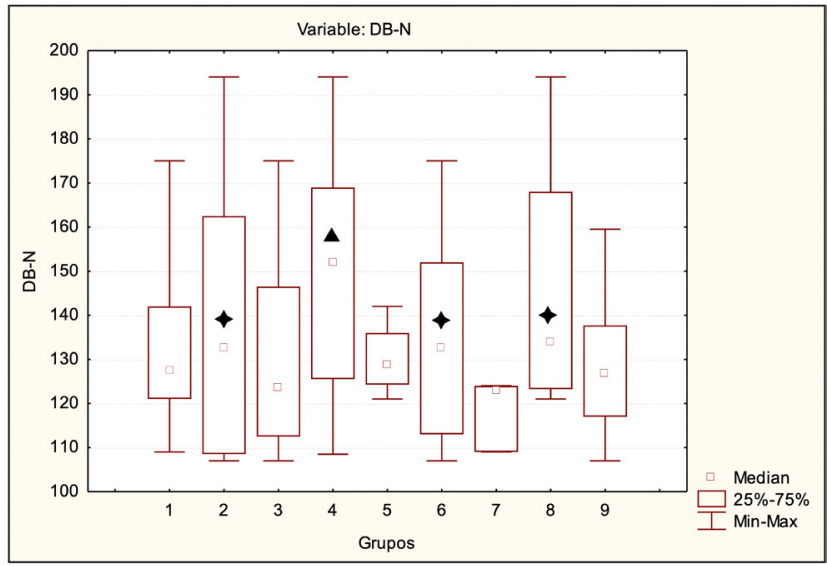

Figura 1. Daño del ADN por ensayo cometa alcalino y neutral en las pacientes agrupadas de acuerdo con la presencia de APF-C, el tratamiento recibido y el tiempo de remisión. Se representa la mediana acotada por el 25 y 75 percentiles ( $1^{\text {er }}$ y $3^{\text {er }}$ cuartiles, respectivamente). El tercer cuartil de las mujeres controles representa el punto de corte del daño del ADN. A) Daño basal del ADN determinado por ensayo cometa alcalino (DB-A) en los diferentes grupos. B) Daño basal del ADN determinado por ensayo cometa neutral (DB-N) en los diferentes grupos. Grupo 1: pacientes con APF-C (DB-A: 32,53 $\pm 4,7$; DB-N: 132,5 $\pm 4,5$ ); Grupo 2: pacientes sin APF-C (DB-A: $30,83 \pm 4,8$; DB-N: 139,3 \pm 11 ); Grupo 3: pacientes con politerapia (QTP + RTP) (DB-A: 36,43 $\pm 4,5$; DB$\mathrm{N}$ : $130 \pm 5,8$ ); Grupo 4: pacientes con monoterapia (QTP o RTP) (DB-A: 25,1 $\pm 7,5$; DB-N: 150,2 \pm 12.7 ); Grupo 5: pacientes que no recibieron QTP/RTP (DB-A: 26,25 $\pm 5,5$; DN-N: 130,12 $\pm 4,4$ ); Grupo 6: pacientes con tiempo de remisión de 1 año (DB-A: 33,53 $\pm 4,3$; DB-N: 135,5 \pm 5,5); Grupo 7: pacientes con tiempo de remisión < 1 año (DB-A: $37 \pm 8,5$; DB-N: 118,7 $\pm 4,8$ ); Grupo 8: pacientes con tiempo de remisión > 1 año (DB-A: $21,12 \pm 4,8$; DB-N: 145,6 $\pm 16,7$ ); Grupo 9: mujeres controles (DB-A: $24,35 \pm 2,4$, 3er cuartil: 30 UA; DB-N: $128 \pm 3$, 3er cuartil: $137.75 \mathrm{UA})$. Kruskal-Wallis ANOVA para comparación de varios grupos: $p>0,05$. Prueba U de Mann-Whitney para comparación de dos grupos: $\mathrm{p}<0,05$ ( $*$ ); valor cercano a $\mathrm{p}<0,05$ (४). Valor por encima del 3er cuartil del daño del ADN (४)
Daño basal del ADN en las pacientes con base en los puntos de corte del grupo control

Al analizar el daño del ADN de las pacientes respecto a los valores de las mujeres controles, dicotomizados en cuartiles, se identificaron diferencias individuales de potencial importancia biológica. El tercer cuartil, que representa el $75 \%$, fue tomado como valor de referencia o punto de corte. La última columna de la derecha de la Tabla 2 refleja estos valores determinados para el total de las mujeres controles, así como por grupo de edad (Tabla 2). El análisis de los valores medios de ambos tipos de daño en las pacientes indicó que las roturas de simple hebra del $A D N$ se encuentran aumentadas por encima del punto de corte en el total de las pacientes (DB-A: 31,89 vs 30), así como en las mayores de 25 años (DBA: 30,26 vs 27,5 ) y en las más jóvenes (DB-A: 35,85 vs 34 ). Por otra parte, las roturas de doble hebra, determinadas por ensayo cometa neutral, estuvieron aumentadas por encima del punto de corte en las pacientes mayores (DB-N: 144,4 vs 135 ).

El análisis de los valores individuales del daño basal del ADN en relación también a los puntos de corte, en las pacientes agrupadas según el tiempo de remisión (Tabla 3), permitió observar que en los tiempos de dos y tres meses hubo un predominio del DB-A elevado, mientras que en los tiempos largos prevaleció un incremento del DB-N. En el grupo mayoritario de un año de remisión, ambos tipos de roturas estuvieron aumentadas en una proporción similar, con ocho pacientes afectadas para cada tipo de rotura del ADN. A su vez, al tener en cuenta el tratamiento recibido con QTP y/o RTP, nueve pacientes presentaron aumento de uno u otro tipo de roturas del ADN. De acuerdo con los APF-C, 11 pacientes tuvieron afectados los valores de uno $\mathrm{u}$ otro tipo de daño del ADN.

Al considerar el total de pacientes, el 41,6\% (10/24) tuvo aumento de roturas de simple $\mathrm{y} / \mathrm{o}$ doble hebra del ADN respecto a los puntos de corte para las edades correspondientes. En este subgrupo se observó que la mayoría fue mayor de 25 años, en la que seis presentaron elevación en el DB-A y nueve en el DB-N, con predominio del grupo de CM, donde dos exhibieron incremento concomitante de ambos tipos de daño del ADN. 
La Tabla 3 también muestra los valores utilizados como control positivo, correspondientes a una paciente con $C M$ que estaba recibiendo quimioterapia en el momento de realizar la investigación. En relación con los puntos de corte de las mujeres controles mayores de 25 años, ambos tipos de roturas de hebra del ADN están incrementadas, 7 veces para las roturas de simple hebra y 1,6 veces para las de doble hebra del ADN.

Tabla 3. Distribución de los niveles de DB-A y DB-N del ADN en las pacientes con cáncer en remisión, según el tiempo de remisión del cáncer. Se describe si recibieron QTP y/o RTP, la localización del cáncer y la presencia de APF de cáncer

\begin{tabular}{|c|c|c|c|c|c|c|c|}
\hline \multirow[t]{2}{*}{$\begin{array}{l}\text { Tiempo } \\
\text { de } \\
\text { remisión }\end{array}$} & \multicolumn{2}{|c|}{$\begin{array}{c}\text { Tratamiento } \\
\text { antineoplásico con QTP } \\
\text { y/o RTP }\end{array}$} & \multirow[t]{2}{*}{ Localización } & \multirow[t]{2}{*}{ APF cáncer } & \multirow[t]{2}{*}{ Edad } & \multirow[t]{2}{*}{$\begin{array}{l}\text { DB-A } \\
\text { (UA) }\end{array}$} & \multirow[t]{2}{*}{$\begin{array}{l}\text { DB-N } \\
\text { (UA) }\end{array}$} \\
\hline & QTP & RTP & & & & & \\
\hline \multirow{2}{*}{2 meses } & $A, C, T$ & RTP & $C M$ & $\begin{array}{c}\text { Mama (I y II grado) y otras localizaciones (II } \\
\text { grado) }\end{array}$ & 39 & 27 & 109 \\
\hline & A, C, T & RTP & $C M$ & Mama (I grado) y otras localizaciones (II grado) & 60 & $30^{*}$ & 124 \\
\hline 3 meses & $P$ & RTP & CG & Diferentes localizaciones (I y II grado) & 33 & $54^{*}$ & 123 \\
\hline \multirow{17}{*}{1 año } & - & - & CEGS & Diferentes localizaciones (II grado) & 17 & $36^{*}$ & 130 \\
\hline & QTP? & RTP & $\mathrm{Rb}-\mathrm{U}$ & Diferentes localizaciones (III grado) & 19 & $35^{*}$ & 113 \\
\hline & QTP? & RTP & $\mathrm{N}$ & - & 19 & 28,5 & 112,5 \\
\hline & QTP? & - & $N$ & - & 20 & $61^{*}$ & 108,5 \\
\hline & QTP? & RTP & TW & - & 21 & 18 & 107 \\
\hline & QTP? & RTP & LLNH & - & 24 & $40,5^{*}$ & 107,5 \\
\hline & QTP? & - & $M$ & - & 35 & 25 & $162,5^{* *}$ \\
\hline & $\mathrm{A}, \mathrm{C}, \mathrm{T}$ & RTP & $C M$ & Mama y otras localizaciones & 44 & $75^{*}$ & 115,5 \\
\hline & $A, C, T$ & - & $C M$ & - & 46 & 24,5 & $169^{* *}$ \\
\hline & $\mathrm{A}, \mathrm{C}, \mathrm{T}$ & RTP & $C M$ & Mama y otras localizaciones (I y II grados) & 47 & 18 & $175^{* *}$ \\
\hline & - & - & CG & Cervicouterino y otras localizaciones (I y II grados) & 55 & 11 & 127,5 \\
\hline & $\mathrm{A}, \mathrm{C}, \mathrm{T}$ & RTP & $C M$ & - & 56 & $41^{*}$ & 132,5 \\
\hline & $A, C, T$ & RTP & $C M$ & Mama y otras localizaciones & 59 & $52^{* a}$ & $152^{* * a}$ \\
\hline & A, C, T & RTP & $C M$ & Mama y otras localizaciones & 61 & $49,5^{* a}$ & $142^{* * a}$ \\
\hline & $A, C, P$ & RTP & CG & Diferentes localizaciones (I y II grado) & 62 & 17,5 & $146,5^{* *}$ \\
\hline & - & RTP & $C M$ & Mama (I grado) y otras localizaciones (I y II grado) & 64 & 13,5 & $141,5^{* *}$ \\
\hline & $\mathrm{A}, \mathrm{C}, \mathrm{T}$ & RTP & $C M$ & - & 71 & 24 & $160,5^{* *}$ \\
\hline 2 años & - & - & $C M$ & Mama y otras localizaciones (II grado) & 48 & 26 & 121 \\
\hline 4 años & - & - & $\mathrm{Rb}-\mathrm{B}$ & RB Bilateral (I grado) Otras localizaciones (II grado) & 18 & 32 & $142^{* *}$ \\
\hline 5 años & $A, C, T$ & - & $C M$ & - & 46 & 15 & $194^{* *}$ \\
\hline 11 años & $\mathrm{A}, \mathrm{C}, \mathrm{T}$ & - & $C M$ & Mama y otras localizaciones (I grado) & 59 & 11,5 & 125,5 \\
\hline Actual & $\begin{array}{c}\text { A, C } \\
\text { (1ra sesión) }\end{array}$ & - & $C M$ & Mama y otras localizaciones (I y II grado) & 43 & $194^{*}$ & $215^{* *}$ \\
\hline
\end{tabular}

Leyenda: A: adriamicina < C: ciclofosfamida: T: taxol; P: cisplatino. QTP?: no se obtuvo el dato de la quimioterapia realizada. RTP: radioterapia. CM: Cáncer de mama; CG: Cáncer Ginecológico; CEGS: Carcinoma embrionario de Glándulas Suprarrenales; Rb-U: Retinoblastoma unilateral; Rb-B: Retinoblastoma bilateral Nb: Neuroblastoma; TW: Tumor de Wilms; LLNH: Linfoma Linfoblástico No Hodking; M: Melanoma. DB-A: daño basal del ADN determinado por ensayo cometa alcalino; DB-N: daño basal del ADN determinado por ensayo cometa neutral; UA: Unidades Arbitrarias. Itálica: control positivo de valores elevados de daño del ADN en paciente con CM que recibió la primera sesión de QTP

* Valor por encima del tercer cuartil del daño por roturas de simple hebra de las mujeres controles

** Valor por encima del tercer cuartil del daño por roturas de doble hebra de las mujeres controles

a Indica aumento de ambos tipos de daño del ADN por encima del tercer cuartil de las mujeres controles 


\section{Daño basal del ADN en las pacientes y consumo de suplementos nutricionales antioxidantes}

Un grupo de las pacientes había realizado tratamiento con antioxidantes previo al estudio $(\mathrm{N}=6)$, mientras el resto no lo realizó $(\mathrm{N}=18)$. La comparación entre ambos grupos (Tabla 4) reflejó que el DB-A fue significativamente más bajo en las que habían consumido tales suplementos $(p=0,006)$, mientras que no hubo diferencias para el DB-N $(p=0,386)$. Al comparar este grupo con las mujeres controles $(N=24)$, no hubo diferencias en ninguno de los daños basales determinados (DB-N: $p=0,213$ : DB-A: $p=$ $0,194)$, aunque el $D B-N$ fue más elevado, teniendo en cuenta el punto de corte correspondiente del total de las mujeres controles (DB-N: 141,8 vs. 137,75 ). Contrariamente, las pacientes que no consumieron antioxidantes presentaron aumento significativo del daño basal por roturas de simple hebra del ADN (DB$A: p=0,0136)$. El daño por roturas de doble hebra en este grupo fue normal (DB-N: 132,8 vs 137,75), al considerar el punto de corte del total de las mujeres controles.

Tabla 4. Niveles del DB-N y el DB-A del ADN en las pacientes con cáncer en relación con el consumo de antioxidantes

\begin{tabular}{|c|c|c|c|}
\hline A & $\begin{array}{c}\text { Pacientes } \\
\text { (Antioxidantes) } \\
\mathrm{N}=6\end{array}$ & $\begin{array}{c}\text { Pacientes } \\
\text { (No Antioxidante) } \\
\mathrm{N}=18\end{array}$ & $\mathrm{p}$ \\
\hline Edad & $48,3 \pm 15,9$ & $40,7 \pm 18$ & 0,404 \\
\hline DB-N & $141,8 \pm 10,2$ & $132,8 \pm 5,6$ & 0,386 \\
\hline DB-A & $17,8 \pm 2,9$ & $36,6 \pm 3,8$ & 0,006 \\
\hline B & $\begin{array}{c}\text { Pacientes } \\
\text { (Antioxidantes) } \\
\mathrm{N}=6\end{array}$ & $\begin{array}{c}\text { Controles } \\
\mathrm{N}=24\end{array}$ & $\mathbf{p}$ \\
\hline Edad & $48,3 \pm 15,9$ & $37,91 \pm 12,7$ & 0,073 \\
\hline DB-N & $141,8 \pm 10,2$ & $128 \pm 3$ & 0,213 \\
\hline DB-A & $17,8 \pm 2,9$ & $24,35 \pm 2,4$ & 0,194 \\
\hline C & $\begin{array}{c}\text { Pacientes } \\
\text { (No Antioxidantes) } \\
\mathrm{N}=18\end{array}$ & $\begin{array}{c}\text { Controles } \\
\mathrm{N}=24\end{array}$ & p \\
\hline Edad & $40,7 \pm 18$ & $37,91 \pm 12,7$ & 0,731 \\
\hline DB-N & $132,8 \pm 5,6$ & $128 \pm 3$ & 0,732 \\
\hline DB-A & $36,6 \pm 3,8$ & $24,35 \pm 2,4$ & 0,013 \\
\hline
\end{tabular}

Leyenda: A: comparación entre pacientes con o sin tratamiento antioxidante. B: comparación entre pacientes con tratamiento antioxidante y el total de controles. C: comparación entre pacientes sin tratamiento antioxidante y el total de controles; DB-A: daño basal del ADN determinado por ensayo cometa alcalino en unidades arbitrarias, que presenta las roturas de simple hebra del ADN; DB-N: daño basal del ADN determinado por ensayo cometa neutral en unidades arbitrarias, que representa las roturas de doble hebra; $p<0,05$, prueba $U$ de MannWhitney.

\section{Daño basal del ADN en las pacientes con cáncer de mama y tratamiento con tamoxifeno}

Las 13 pacientes con $C M$ incluidas en el análisis comparativo se encontraban realizando tratamiento con tamoxifeno en el momento del estudio. Al comparar este grupo con respecto a las mujeres controles mayores de 25 años (Tabla 5A), no hubo diferencias significativas en el daño basal del ADN (DB-N: $p=0,216$ y DB-A: $p=0,131$ ). Teniendo presente que cuatro de las pacientes habían consumido antioxidantes, se compararon las pacientes según si habían consumido o no antioxidantes y con las mujeres controles mayores de 25 años.

Tabla 5. Niveles del DB-N y el DB-A del ADN en las pacientes con cáncer de mama en remisión con tratamiento de tamoxifeno.

\begin{tabular}{|c|c|c|c|}
\hline A & $\begin{array}{c}\text { Pacientes } \\
\text { (Tamoxifeno) } \mathrm{N}=13\end{array}$ & $\begin{array}{c}\text { Controles } \\
>25 \text { años } N=17\end{array}$ & $\mathbf{p}$ \\
\hline Edad & $53,8 \pm 9,4$ & $45,9 \pm 5,9$ & 0,052 \\
\hline DB-N & $143,2 \pm 7,1$ & $129 \pm 3,6$ & 0,216 \\
\hline DB-A & $31,3 \pm 5,1$ & $22,7 \pm 2,9$ & 0,131 \\
\hline B & $\begin{array}{c}\text { Pacientes } \\
\text { (Tamoxifeno) } \\
\text { (No antioxidantes) } \\
\text { N=9 }\end{array}$ & $\begin{array}{c}\text { Pacientes } \\
\text { (Tamoxifeno) } \\
\text { (Antioxidantes) } \\
\mathrm{N}=4\end{array}$ & P \\
\hline Edad & $53,7 \pm 10,1$ & $54 \pm 8,9$ & 0,877 \\
\hline DB-N & $138,9 \pm 8,9$ & $152,7 \pm 17,9$ & 0,280 \\
\hline DB-A & $37,7 \pm 6,2$ & $16,8 \pm 8,7$ & 0,020 \\
\hline C & $\begin{array}{c}\text { Pacientes } \\
\text { (Tamoxifeno) } \\
\text { (No antioxidantes) } \\
\mathrm{N}=9\end{array}$ & $\begin{array}{l}\text { Controles } \\
>25 \text { años } \\
N=17\end{array}$ & $\mathbf{p}$ \\
\hline Edad & $53,7 \pm 10,1$ & $45,9 \pm 5,9$ & 0,100 \\
\hline DB-N & $138,9 \pm 8,9$ & $129 \pm 3,6$ & 0,434 \\
\hline DB-A & $37,7 \pm 6,2$ & $22,7 \pm 2,9$ & 0,033 \\
\hline D & $\begin{array}{c}\text { Pacientes } \\
\text { (Tamoxifeno) } \\
\text { (Antioxidantes) } \mathrm{N}=4\end{array}$ & $\begin{array}{l}\text { Controles } \\
>25 \text { años } \\
\mathrm{N}=17\end{array}$ & p \\
\hline Edad & $54 \pm 8,9$ & $45,9 \pm 5,9$ & 0,151 \\
\hline DB-N & $152,7 \pm 17,9$ & $129 \pm 3,6$ & $0,054\left(^{*}\right)$ \\
\hline DB-A & $16,8 \pm 8,7$ & $22,7 \pm 2,9$ & 0,370 \\
\hline
\end{tabular}

Leyenda: A: comparación entre pacientes con $\mathrm{CM}$ y tamoxifeno vs. mujeres controles mayores de 25 años. B: comparación entre pacientes con tratamiento de tamoxifeno respecto al consumo de antioxidantes. C: comparación entre pacientes con tamoxifeno y sin antioxidantes vs. mujeres controles mayores de 25 años. D: comparación entre pacientes con tamoxifeno y antioxidantes vs. mujeres controles mayores de 25 años. DB-A: daño basal del ADN determinado por ensayo cometa alcalino en unidades arbitrarias, que presenta las roturas de simple hebra del ADN; DB-N: dano basal del ADN determinado por ensayo cometa neutral en unidades arbitrarias, que representa las roturas de doble hebra; $\mathrm{p}<0,05 ;\left(^{*}\right)$ valor cercano a la significación estadística, prueba U de Mann-Whitney. 
Se obtuvo que las pacientes con tratamiento de tamoxifeno que no utilizaron antioxidantes presentaron niveles mayores de roturas de simple hebra del ADN que fueron significativos, respecto a las pacientes que realizaron ambos tratamientos (DB-A: $p=0,020)$, (Tabla 5B) y a las mujeres controles (DB-A: $p=0,033)$, (Tabla $5 C$ ). Por su parte, el grupo de pacientes que realizó los dos tratamientos mostró similitud con las mujeres controles (Tabla $5 D$ ) en las roturas de simple hebra del ADN (DB$A: p=0,370$ ). Las roturas de doble hebra del $A D N$, aunque estadísticamente estuvieron cercanas a la significación estadística ( $D B-N$ : $p=0,054)$, estuvieron elevadas con respecto al punto de corte del total de las mujeres controles (DB-N: 152,7 vs 137,75).

\section{Discusión}

Los valores medios de daño del ADN de las pacientes, determinado por ambos métodos, fueron semejantes a los de las mujeres controles (Tabla 2A, puesto que las diferencias entre los grupos no tuvieron significación estadística. En personas sanas, los niveles de daño al $A D N$ se mantienen relativamente constantes por la contribución de los sistemas de reparación (19). Es posible conjeturar que la presencia de valores medios normales de este marcador en estas pacientes se debe a una reparación eficiente, que permite controlar el daño imputado por factores modificadores como el ambiente, el tratamiento recibido, la dieta, el estilo de vida y el metabolismo. Si tenemos en cuenta que las pacientes se encontraban en seguimiento clínico por remisión del cáncer y no presentaban la enfermedad en el momento de realizar la investigación, es posible considerar que su eliminación esté determinando valores normales de daño del ADN. Relacionado con esto, se ha reportado que la resección quirúrgica de tumores ha restablecido los niveles de antioxidantes del plasma y ha reducido los niveles de daño oxidativo en linfocitos de pacientes con cáncer (20).

Al analizar el daño del ADN por edades de mayores y menores de 25 años, no hubo diferencias entre los grupos de estudio (Tabla 2B y 2C). Sin embargo, la comparación entre pacientes con base en estos grupos de edades mostró diferencias significativas (Tabla 2D) y reveló que el aumento del daño por roturas de doble hebra del ADN estuvo asociado al incremento de la edad. De hecho, nueve pacientes mayores de 25 años presentaron aumento de este tipo de roturas del $A D N$ en relación con el punto de corte de las mujeres controles, mientras que solo una paciente joven exhibió el DB-N elevado (Tabla 3). Este hallazgo podría deberse a una eficacia reducida en la reparación de este tipo de roturas en las de más edad (21). Específicamente, se ha encontrado una relación inversa entre la reparación de roturas de doble hebra del ADN y la edad, mientras que la reparación de roturas de simple hebra se mantiene conservada hasta edades avanzadas (22). En las mujeres controles no se observó esta relación entre el daño del ADN y la edad. Esto podría estar relacionado con la composición de las edades de este grupo, que presentó un promedio de edad más bajo que el de las pacientes debido a una menor representación de edades mayores de 55 años. No obstante, los tamaños muestrales no discordaron y no hubo diferencias significativas globales entre las edades de ambos grupos.

De las 24 pacientes estudiadas, el 41,6\% presentó valores individuales incrementados de roturas de simple y doble hebra del ADN, en relación con el tercer cuartil del grupo control, aun cuando no hubo diferencias significativas globales. Específicamente, la presencia de antecedentes familiares de cáncer en 11 de ellas podría ser un factor predisponente que pudiera estar contribuyendo a niveles elevados de daño del ADN, aun cuando no se pudo tener el dato del grado de parentesco en todas ellas (Tabla 3). Aunque el análisis, de acuerdo con la presencia o no de estos antecedentes, no mostró diferencias significativas en comparación con las mujeres controles, ciertamente el grupo con APF-C presentó el DB-A aumentado por encima del punto de corte del grupo control. Al respecto, se ha reportado en linfocitos de la sangre una relación entre la historia familiar de cáncer y la presencia de inestabilidad genómica, una sensibilidad incrementada al efecto genotóxico de mutágenos, así como una capacidad de reparación disminuida del ADN. En este contexto, se ha sugerido que la acumulación del daño del ADN podría contribuir a la carcinogénesis, unida a la exposición ambiental y a una susceptibilidad genética $(23,24)$. Por un lado, mutaciones germinales en uno de los alelos de los genes BRCA1, BRCA2 $(6,25)$ o RB (7), así como variantes polimórficas de genes de la reparación han sido asociadas con un riesgo incrementado de cáncer. Estas variantes pueden resultar en la pérdida de la funcionalidad de muchos genes, lo que es un elemento clave en la susceptibilidad al cáncer en individuos de familias 
con cáncer y también en individuos de la población general $(26,27)$. En correspondencia con lo anterior, es posible conjeturar que las 11 pacientes con historia familiar de cáncer presentan una mayor susceptibilidad genética para la enfermedad, y sería pertinente conocer si son portadoras de estos marcadores genéticos. Particularmente, el grupo mayoritario correspondió a $\mathrm{CM}$, en el que seis con daño elevado del ADN presentaron antecedentes familiares de CM y, además, específicamente de ovario y próstata en dos de ellas. Teniendo en cuenta la relación entre mutaciones en los genes BRCA y un mayor riesgo de cáncer de mama, ovario y próstata $(6,26)$, unido a la presencia de antecedentes familiares de estas localizaciones, podría plantearse que tienen una mayor susceptibilidad genética al cáncer. Curiosamente, estas dos pacientes presentaron aumento de ambos tipos de roturas del ADN por encima de los respectivos puntos de corte de las mujeres controles. Por otra parte, en todas las que tuvieron APF se recoge la presencia de otras localizaciones de cáncer, donde otras cuatro mujeres mostraron específicamente elevación del DB-N. Como se conoce, los genes BRCA participan en la reparación de las roturas de doble hebra del ADN, y mutaciones en estos genes también han sido implicadas en el riesgo de cáncer de otras localizaciones $(28,29)$. Por lo que cabría plantearse la posibilidad de que algunas de estas pacientes fueran portadoras de mutaciones en estos genes.

Llamó la atención que, aun cuando no hubo diferencias significativas, el grupo de pacientes sin APF-C presentó los niveles medios del DB-N por encima del punto de corte de las mujeres controles. Cabe señalar al respecto que, dentro de este grupo, las que tuvieron el DB-N elevado fueron mayores de 25 años, y además todas habían estado expuestas a tratamientos con QTP y/o RTP. Si consideramos que diferentes factores pueden contribuir al daño del $A D N$, el incremento en las roturas de doble hebra pudiera deberse al efecto combinado de la edad, el tratamiento antineoplásico que recibieron, y la presencia de alguna susceptibilidad individual no identificada, que no implica a los APF-C, además de la dieta, el estilo de vida, la exposición ambiental, el metabolismo celular $(11,30,31)$.

De las 20 pacientes que estuvieron bajo la influencia de QTP y/o RTP, nueve de ellas presentaron aumento en uno u otro tipo de roturas del ADN (Tabla 3) con respecto a los puntos de cortes de las mujeres controles. Aunque no se tuvo el dato de los fármacos utilizados en el total de ellas, teniendo en cuenta los efectos carcinogénicos acumulativos de este tipo de terapia, la elevación de ambos tipos de roturas del ADN en este subgrupo podría estar relacionada con el tratamiento antineoplásico recibido, unido a una reparación ineficiente del ADN $(11,12)$. De hecho, el análisis, según el tratamiento recibido, mostró diferencias significativas en el DB-A de las pacientes politratadas (QTP + RTP) en relación con las mujeres controles, mientras que las que realizaron monoterapia (QTP o RTP) presentaron valores medios cercanos a la significación estadística en el DB-N (Figura 1). Teniendo presente que tanto la QTP como la RTP producen roturas de simple y doble hebra del $A D N$, podría esperarse que las que recibieron politratamiento tuvieran también niveles significativos del daño por roturas de doble hebra del ADN, debido a la acción sinérgica o aditiva de ambos tipos de terapia; aun más, cuando la mayoría realizó esquemas con varios agentes quimioterapéuticos unidos a la RTP. Al tratarse de pacientes en proceso de remisión, es presumible que, mediante el sistema de respuesta al daño del ADN, se activaran los mecanismos de reparación y actuaran en la eliminación de este. El mecanismo de recombinación no homóloga es uno de los mecanismos celulares de reparación que revierten las roturas de doble hebra del ADN. Es el que predomina, ya que está activo a lo largo del ciclo celular, y aunque es propenso a error puede actuar rápidamente ante el daño de doble hebra producido por la RTP $(31,32)$. En tal caso, podría ser particularmente el mecanismo operante en las que realizaron QTP + RTP para reparar y mantener las roturas de doble hebra del ADN dentro de los valores de referencia de las mujeres controles. Al respecto, estudios realizados en linfocitos de sangre periférica de pacientes con riesgo de cáncer de mama familiar o cáncer de mama esporádico, expuestos a irradiación, reportaron que la reparación no homóloga estuvo incrementada en comparación con personas sanas (31).

El DB-A, que en las pacientes politratadas estuvo elevado, representa el daño por roturas de simple hebra generadas durante la reparación del daño oxidativo del ADN, producido por el metabolismo oxidativo, así como por la acción de agentes externos como la QTP y RTP, unidos a exposición ambiental, entre otros factores (31). Los agentes quimioterapéuticos y la RTP, además de toxicidad inmediata, producen efectos tóxicos a largo plazo 
$(10,11)$. Estos efectos tóxicos se ejercen sobre otros tejidos que no son los blancos de estas terapias, por ejemplo, el tejido linfoblastoide. Los efectos a largo plazo o tardíos se manifiestan posteriormente a los seis meses o más después del tratamiento, lo que se ha relacionado con la hipersensibilidad al tratamiento $(31,32)$ De conformidad con lo anterior, varios autores en estudios experimentales en linfocitos de sangre periférica de pacientes con cáncer de mama tratados con RTP encontraron correspondencia entre los niveles bajos de daño del ADN y un riesgo bajo a eventos adversos de la RTP $(31,33)$. Aunque en estos estudios se determinó el daño residual por roturas de doble hebra, y dado que en el presente trabajo no se tuvieron en cuenta los eventos de toxicidad postratamiento, sería de interés determinar en futuros estudios la correlación entre ambos tipos de daño del ADN y la presencia de eventos adversos postratamientos como efectos tardíos. No obstante, teniendo presente que la mayoría de las pacientes politratadas se encontraban en un periodo postratamiento mayor a los seis meses, sería posible considerar que el incremento significativo del DB-A pudiera estar reflejando un efecto tardío postratamiento a nivel de la médula ósea. Como consecuencia del estrés genotóxico, provocado por ambos tipos de terapias, pudiera manifestarse como daño residual por roturas de simple hebra del ADN, al generarse niveles elevados de especies reactivas del oxígeno.

A la vez, debemos tener presente que la sensibilidad individual con la cual se responde a los tratamientos aplicados, dada por polimorfismos genéticos en los genes de los diferentes sistemas de respuesta y reparación del daño del ADN, pudiera explicar los resultados observados (31). De esta manera, un estudio por ensayo cometa alcalino reportó una gran variabilidad interindividual en pacientes con cáncer de mama frente a la poliquimioterapia utilizada, desde la no detección de daño del ADN hasta la cuantificación de niveles elevados por encima de los basales. Esta respuesta estuvo correlacionada con polimorfismos en los genes de la enzima glutatión S-transferasa, enzima detoxificadora implicada en el metabolismo de compuestos xenobióticos. Particularmente, las pacientes que presentaron los genotipos GSTM1 tuvieron mayor daño del ADN (14). De acuerdo con lo anterior, podría conjeturarse sobre la posibilidad de que las pacientes que tuvieron el daño elevado del ADN significativamente presentaran alguna variante polimórfica de esta enzima u otras proteínas involucradas en la eliminación del daño del ADN.

De acuerdo con la teoría de los diferentes niveles de daño del $A D N$ en los diferentes estados de la transformación maligna, el daño elevado del ADN inducido por QTP y/o RTP en células normales, si supera los llamados niveles homeostáticos (normales) de daño, de no ser reparado correctamente podría acumularse y activar vías de señalización oncogénicas que pudieran promover la transformación maligna y el crecimiento incontrolado, con la posible ocurrencia de cáncer secundario (34). Por consiguiente, los niveles elevados del daño del ADN en estas pacientes podrían ser tomados en cuenta como una señal de alerta en el seguimiento clínico del cáncer en remisión.

Partiendo de esta variabilidad individual en la respuesta a los tratamientos antineoplásicos, que implica grados variables de toxicidad y de daño del ADN por encima de los normales, en relación con estos tratamientos antineoplásicos, resulta importante monitorear a los pacientes en el periodo de remisión. Aun en remisión exitosa existe un riesgo incrementado de desarrollar cáncer secundario después de recibir estos tratamientos $(31,32,34)$. Por ejemplo, se ha determinado el riesgo de cáncer secundario después de 10 y 15 años del tratamiento para el cáncer de mama $(8,9)$ y después de 14 años de tratamiento para múltiples cánceres (35). Varios autores han determinado los niveles basales de daño del ADN por ensayo cometa en el cáncer después de finalizar el tratamiento antineoplásico, a los 80 días (12), a los 6 meses y al año $(11,36)$. Otros han planteado la utilidad de este marcador por ensayo cometa al final del tratamiento para determinar la relación con la recurrencia y supervivencia (11) y predecir las probabilidades de remisión del cáncer a los 5 años (14). De manera similar, en el presente trabajo se ha utilizado el ensayo cometa en sus dos variantes para determinar las roturas basales de simple y doble hebra del ADN en pacientes femeninas con cáncer en remisión y la identificación de diferencias individuales de potencial importancia clínica. Aunque los periodos de remisión variaron desde dos meses hasta 11 años, la mayoría $(66,7 \%)$ se encontraba en el año de remisión (Tabla 3). El análisis comparativo de acuerdo con los diferentes tiempos de remisión no informó diferencias significativas con respecto al grupo control. No obstante, en las pacientes con tiempo de remisión de 1 año el DB-A 
se observó aumentado en relación con el punto de corte de las mujeres controles (Figura 1, Grupo 6). Este hallazgo podría estar reflejando un efecto crónico del tratamiento recibido, teniendo en cuenta que la mayoría recibió poliquimioterapia, unida a radioterapia. Al respecto, se ha planteado que el uso de los leucocitos aislados de la sangre como células subrogadas, mediante el ensayo cometa, permite determinar la genotoxicidad crónica y subcrónica (11). Por otro lado, cabría esperar que en el tiempo de remisión < 1 año (dos y tres meses), el daño del ADN estuviera incrementado significativamente, semejante al observado en el control positivo, en el que el DB-A y el DB-N se elevaron siete y aproximadamente dos veces, respectivamente. En correspondencia con este incremento esperado, varios autores obtuvieron niveles significativos de daño del ADN mediante ensayo cometa en pacientes tratadas con radioterapia y quimioterapia combinada $(11,12)$. Sin embargo, se advirtió solo un incremento en las roturas de simple hebra del ADN, con valores semejante al daño cuantificado en el tiempo de remisión de un año (Figura 1, Grupo 7). Esto podría deberse a una respuesta adaptativa como resultado de la activación de los mecanismos de reparación del ADN frente al daño inducido por el tratamiento antineoplásico (11). Contrastó que en el grupo de remisión > 1 año el DB-N estuvo elevado (Figura 1, Grupo 8), en el que dos pacientes contribuyeron al incremento en relación con el punto de corte del grupo control. En una de ellas con $\mathrm{CM}$, se esperaría que transcurridos cinco años los mecanismos de recombinación homóloga y no homóloga, entre otros, eliminaran las roturas de doble hebra del ADN imputadas por la poliquimioterapia (37). Por otra parte, la que presentaba $\mathrm{Rb}-\mathrm{B}$ no recibió QTP y/o RTP. Como ya se ha mencionado, factores como la dieta, el estilo de vida, la exposición ambiental, el metabolismo celular $(11,30)$, podrían estar relacionados con el incremento del DB-N en ellas. A su vez, la presencia de una susceptibilidad genética individual, también ya sugerida $(26,27)$, podría estar influenciando el daño del ADN. Especialmente, en esta última afectada de $\mathrm{Rb}-\mathrm{B}$, que presenta antecedentes familiares de la enfermedad en primer grado, la presumible variante heredable de $\mathrm{Rb}$ le atribuye un riesgo incrementado de desarrollar nuevos tumores en tejidos fuera del ojo $(7,38)$.

Estudios recientes han evidenciado la participación de la proteína $\mathrm{Rb}$ en las vías de reparación de las roturas de doble hebra del ADN (7). Esta variabilidad interindividual, observada en ambos tipos de roturas del ADN según el tiempo de remisión, probablemente se deba a la heterogeneidad y al tamaño pequeño de la muestra. No obstante, una investigación reciente ha reportado el seguimiento de pacientes femeninas con cáncer primario de mama durante diferentes periodos de 1, 5, 10 y 15 años en la identificación de cáncer secundario (39).

De modo que los valores elevados de ambos tipos de roturas del $A D N$, identificados respecto a los puntos de corte de las mujeres controles, resultaron informativos en relación con las diferencias individuales de estas pacientes, que pueden ser tomadas en cuenta en el seguimiento clínico ante el posible riesgo de alta recidiva, cáncer secundario y pobre supervivencia $(13,14)$. Análogamente, el uso de cuartiles de los controles se ha reportado en el análisis del daño del ADN por ensayo cometa en el cáncer (18).

El uso de terapias antioxidantes en el cáncer resulta controversial debido a los efectos adversos que pueden provocar en el metabolismo oxidativo, sobre todo si se usan en dosis elevadas, puesto que pueden inhibir las funciones de especies reactivas importantes del oxígeno, como el peróxido de hidrógeno. De este modo, pueden interferir con la eficacia del tratamiento con quimioterapia y radioterapia, que median su acción en parte a través de la generación de radicales libres $(1,40)$. No obstante, se ha planteado que el consumo de multivitaminas y micronutrientes en el rango de las dosis diarias recomendadas puede resultar seguro en el cáncer en régimen de tratamiento con quimioterapia y/o radioterapia. Se estima que, en dosis adecuadas, permiten tolerar mejor los efectos adversos de estas terapias antineoplásicas y restablecer los niveles de antioxidantes que se encuentran deficitarios debido al propio tratamiento (1). En el presente trabajo, un grupo de pacientes realizó tratamiento con suplementos multivitamínicos; específicamente, consumieron una mezcla de vitaminas del complejo $B$ y retinol, mientras una paciente utilizó omega 3. Las vitaminas del complejo $B$ son vitaminas esenciales que intervienen en el funcionamiento fisiológico del organismo, como la síntesis y reparación del ADN, el ciclo de la metilación, el sistema inmune, la respuesta inflamatoria y el metabolismo energético. Además, actúan como cofactores en reacciones enzimáticas (41).

Muchas de estas vitaminas tienen un efecto antioxidante. Por ejemplo, la tiamina (Vitamina B1) está implicada indirectamente como cofactor en la 
vía de síntesis del NADPH (del inglés, nicotinamide adenine dinucleotide phosphate), un agente reductor importante que participa en las reacciones enzimáticas del sistema de la enzima glutatión peroxidasa/reductasa y de la tioredoxina peroxidasa (42). A esto se suma una débil participación, también indirecta, en la vía de regulación de la expresión de genes de enzimas antioxidantes a través de Nrf2/ ARE (del inglés, transciption factor Nfr2/antixidant response element) (43). La rivoflavina (Vitamina B2) es convertida a dos cofactores importantes, el FMN (del inglés, Flavin Mononucleotide) y el FDA (del inglés, Flavin Adenine Dinucleotide) que participan en numerosas reacciones de óxido-reducción, como las del sistema de las enzimas glutatión reductasa/xantina oxidasa. Igualmente, influye en las concentraciones de las enzimas antioxidantes superóxido dismutasa, catalasa y glutatión peroxidasa, al parecer a través de la inhibición de la vía de señalización proinflamatoria de $\mathrm{NfkB}$ (del inglés, nuclear factor $\mathbf{k B}$ ), por lo que realiza una importante función en el estatus antioxidante celular. Su uso en la prevención del cáncer ha sido ilustrado en varios estudios (44). La nicotinamida (forma de amida de la vitamina 3), es un precursor del NAD+ (del inglés, Nicotinamide Adenine Dinucleotide), un cofactor enzimático de reacciones redox para la producción de energía, y su estatus ha sido relacionado con la regulación de la estabilidad genómica, debido al alto consumo de energía de los mecanismos de reparación del ADN (45). La piridoxina (vitamina 6) ejerce su acción antioxidante al neutralizar directamente algunos radicales, lo que puede tener un efecto en la peroxidación lipídica, mientras que indirectamente contribuye a regular los niveles de homocisteína. La auto oxidación de la homocisteína en altas concentraciones genera radicales libres y produce incremento del estrés oxidativo. En consecuencia, los niveles de cisteína pueden alterarse y afectarse la síntesis de GSH (del inglés, reduced glutathione), una molécula celular antioxidante importante. De hecho, pareció mejorar la capacidad antioxidante en pacientes con carcinoma hepatocelular, posterior a la resección del tumor (46). Un mecanismo semejante se ha descrito para el ácido fólico (vitamina B9) (47), del cual se ha reportado riesgo disminuido de cáncer de mama en mujeres altas consumidoras de esta vitamina (44). La cianocobalamina (vitamina B12) destaca por atribuírsele varias propiedades antioxidantes entre las se menciona la neutralización directa de especies reactivas del oxígeno, como el anión superóxido; indirectamente, contribuye a preservar el GSH y a reducir los niveles de estrés oxidativo producido por concentraciones altas de homocisteína y productos avanzados de la glicación de proteínas. Se ha sugerido que en concentraciones subclínicas podría mediar el estrés oxidativo y contribuir a la carcinogénesis mediante la oxidación del ADN (47).

El retinol (vitamina A), otra de las vitaminas de la mezcla utilizada por las pacientes, participa en la regulación de la proliferación y la diferenciación, la activación de supresores tumorales, a través de la activación de factores de la transcripción específicos. Al haberse evidenciado que varios tipos de cánceres no expresan una de las proteínas de unión del retinol en el citosol, involucrada en la biodisponibilidad de este, se ha sugerido la utilización de esta vitamina en la prevención y tratamiento del cáncer (48). Por último, el ácido graso de cadena larga omega 3 ha sido implicado en la inhibición de la vía de señalización proinflamatoria de $N f_{k B}$ y en la reducción de derivados lipídicos proinflamatorios. Estudios preclínicos y de casos y controles han apuntado hacia su utilización en la disminución del riesgo de cáncer (49).

De modo que, en teoría, la acción de la mezcla de vitaminas del complejo $B$ y retinol, y de omega 3, en las pacientes que consumieron estos suplementos, podría promover una disminución del impacto del estrés oxidativo causado por los tratamientos antineoplásicos y otros factores que contribuyen al daño del $A D N$. Estas mostraron disminución significativa en el daño del ADN por roturas de simple hebra, mientras que no hubo efecto desde el punto de vista estadístico en las de doble hebra, aunque estuvieron por encima del punto de corte de las mujeres controles (Tabla 4A y 4C). Sin embargo, el efecto observado en el DB-A y el DB-N podría no deberse a la acción antioxidante de los suplementos, al tiempo que hubo factores no controlados como la dosis, la composición del suplemento empleado, el consumo de frutas y vegetales y la presencia de polimorfismos genéticos en las enzimas antioxidantes (50), que pudieron influir en los resultados obtenidos. Por otra parte, el origen sintético de los suplementos utilizados, unido a un posible efecto de estrés reductivo (antioxidativo), podrían contribuir a causar mayor daño (41), lo que podría relacionarse con el incremento observado en las roturas de doble hebra del ADN, aunque no significativo. 
El tamoxifeno es una droga con efecto antiestrogénico que, aunque presenta efectos beneficiosos en la quimioterapia y la quimio prevención del cáncer de mama, se ha asociado con un riesgo incrementado de cáncer endometrial como segundo neoplasma maligno $(51,52)$. Su efecto carcinogénico se ha relacionado con la formación de aductos covalentes con el ADN (52) y con una alteración de la señalización del receptor alfa de estrógeno y la vía de respuesta y reparación del daño del $\operatorname{ADN}(51,52)$ en el tejido uterino. Sin embargo, la formación de aductos de ADN ocurre a niveles tan bajos en el tejido uterino, durante el tratamiento oral con este agente, que resulta poco probable que este sea el mecanismo que dirija el desarrollo de cáncer de endometrio (52).

En nuestro estudio todas las pacientes con cáncer de mama se encontraban consumiendo tamoxifeno, lo que pareció no modificar globalmente los valores promedios de daño del ADN con respecto al de las mujeres controles (Tabla 5). Una investigación semejante evaluó el daño potencial que puede provocar el tamoxifeno en el ADN de linfocitos periféricos y células de cáncer de mama por ensayo cometa alcalino y neutral. Los resultados mostraron la presencia de roturas de simple y doble hebra del ADN y de purinas y pirimidinas oxidadas en ambos tipos de células. En las condiciones experimentales utilizadas, se observó, además, que las roturas de doble hebra del ADN no se repararon completamente en los linfocitos de la sangre (53). De forma interesante, este tipo de daño del ADN se encontró elevado en las pacientes analizadas, por encima del correspondiente punto de corte. A su vez, se planteó que este medicamento parece ejercer su efecto deletéreo en el $A D N$ a través de la generación de radicales libres, al obtenerse que fuera modulado por antioxidantes (54). En concordancia con lo anterior, en nuestro trabajo el daño basal del ADN por roturas de simple hebra fue más bajo en las pacientes que realizaron tratamiento con tamoxifeno y antioxidantes respecto a las que no consumieron los suplementos, mientras que fue similar al de las mujeres controles. Dado el número pequeño de la muestra analizada, se requieren estudios futuros que permitan comprobar los resultados obtenidos y controlar la posible presencia de factores confusores.

De manera que la aplicación de las dos variantes del ensayo cometa en el presente trabajo permitió identificar diferencias individuales con potencial valor clínico en las pacientes estudiadas. Teniendo en cuenta que el daño del ADN es crítico en la génesis del cáncer, el continuo monitoreo de estas podría contribuir a disminuir el riesgo de cáncer secundario $y$, por ende, favorecer una mejor sobrevida. Durante el seguimiento clínico, el médico especialista puede orientar acciones encaminadas fundamentalmente a prevenir el daño del ADN, y modificar factores del estilo de vida que inciden sobre los niveles basales de este (55), como la modificación de la dieta y la realización de ejercicio físico. Particularmente, reducir el consumo de alimentos y hábitos dietéticos asociados a la recurrencia del cáncer, a la inflamación y el estrés oxidativo (54); y aumentar el consumo de aquellos que mejoren la capacidad de reparación del ADN (41). Además, asegurar una cantidad adecuada de nutrientes específicos y selectivos vinculados a la prevención del cáncer, a modo de establecer una aproximación individual dentro del amplio espectro de pacientes (54). Se plantea que la nutrición personalizada es probablemente la más efectiva para contrarrestar en cáncer en todos sus estados (56). Por otra parte, la práctica de ejercicios podría incrementar la capacidad antioxidante del plasma y disminuir los marcadores de daño oxidativo (57), además de mejorar la fuerza muscular, la flexibilidad, la capacidad cardiorrespiratoria y la calidad de vida $(57,58)$.

Los resultados obtenidos, aun cuando proceden de un estudio a pequeña escala en el que la muestra fue heterogénea y pequeña, sugieren la utilidad del ensayo cometa para determinar el daño basal del ADN en el seguimiento clínico del cáncer en remisión. Al mismo tiempo, apuntan hacia la realización de una nueva investigación con un mayor número de pacientes con características más homogéneas. Sería recomendable un estudio prospectivo para determinar el daño basal de ADN por ambas variantes del ensayo cometa desde el momento del diagnóstico, durante el tratamiento antineoplásico y en el periodo de remisión a diferentes intervalos.

\section{Conclusiones}

El presente trabajo constituye un primer estudio en pacientes femeninas cubanas con cáncer en remisión aplicando el ensayo cometa simple, que sienta bases para análisis futuros más completos. Se detectaron diferencias individuales en el daño basal del ADN por roturas de simple y doble hebra en los diferentes grupos estudiados, que resultan de interés para el médico especialista. El daño del ADN por roturas de 
doble hebra estuvo incrementado en relación con la edad, mientras que el daño por roturas de simple hebra estuvo elevado en las pacientes politratadas. El efecto observado en el daño por roturas de simple hebra en aquellas tratadas con tamoxifeno y en las que consumieron antioxidantes, sugiere la necesidad de realizar estudios a mayor escala con el control de posibles factores confusores. No obstante, los resultados obtenidos sugieren que el daño basal de ADN, determinado por ensayo cometa, es un marcador potencialmente útil en el seguimiento clínico de pacientes con cáncer en remisión.

\section{Agradecimientos}

El colectivo de autores agradece la participación en el presente estudio de las pacientes y de las mujeres sanas voluntarias que actuaron como controles.

\section{Bibliografía}

1. Gröber U, Holzhauer P, Kisters Klaus, Holick MF and Adamietz IA. Micronutrients in Oncological Intervention. Nutrients 2016 Mar 12; 8(3):163; 8(163); doi:10.3390/nu8030163

2. Ferlay J, Soerjomataram I, Dikshit R, Eser S, Mathers C, Rebelo $M$ et al. Cancer incidence and mortality worldwide: sources, methods and major patterns in GLOBOCAN 2012. Int J Cancer 2015 Mar 1;136(5):E359-86. doi: 10.1002/ijc.29210.

3. Lynch SM and Rebbeck TR. Bridging the Gap between Biologic, Individual, and Macroenvironmental Factors in Cancer: A Multilevel Approach. Cancer Epidemiol Biomarkers Prev 2013 April; 22(4): 485-495. doi: 10.1158/1055-9965.EPI-13-0010

4. Gunasekarana V, Raj GV and Chand P. A Comprehensive Review on Clinical Applications of Comet Assay. J Clin Diagn Res 2015 Mar; 9(3): GE01-GE05. Published online 2015 Mar 1. doi: $10.7860 / J C D R / 2015 / 12062.5622$

5. O'Connor MJ. Targeting the DNA Damage Response in Cancer. Mol Cell 2015 Nov 19;60(4):547-60. doi: 10.1016/j. molcel.2015.10.040.

6. Gorodetska I, Kozeretska I, Dubrovska A. BRCA Genes: The Role in Genome Stability, Cancer Stemness and Therapy Resistance. J Cancer. 2019; 10(9): 2109-2127. doi: 10.7150/jca.30410

7. Vélez-Cruz R and Johnson DG. The Retinoblastoma (RB) Tumor Suppressor: Pushing Back against Genome Instability on Multiple Fronts. Int. J. Mol. Sci. 2017 Aug 16;18(8):1776; doi:10.3390/ ijms18081776.

8. Grantzau T, Overgaard J. Risk of second non-breast cancer among patients treated with and without postoperative radiotherapy for primary breast cancer: A systematic review and meta-analysis of population-based studies including 522,739 patients. Radiother Oncol 2016 Dec;121(3):402-413. doi: 10.1016/j.radonc.2016.08.017

9. Molina-Montes E, Requena M, Sánchez-Cantalejo E, Fernández MF, Arroyo-Morales M, Espín J et al. Risk of second cancers cancer after a first primary breast cancer: a systematic review and meta-analysis. Gynecol Oncol. 2015 Jan;136(1):158-71. doi: 10.1016/j.ygyno.2014.10.029

10. Ren N, Atyah $\mathrm{M}$, Chen WY, Zhou $\mathrm{CH}$. The various aspects of genetic and epigenetic toxicology: testing methods and clinical applications. J Transl Med. 2017 May 22;15(1):110. doi: 10.1186/s12967-017-1218-4.

11. Gamulin M, Kopjar N, Grgić M, Ramić S, Bišof V, and GarajVrhovac V. Genome Damage in Oropharyngeal Cancer Patients Treated by Radiotherapy. Croat Med J. 2008 Aug;49(4):515-27. PMCID: PMC2525833

12. Sánchez-Suárez $P$, Ostrosky-Wegman $P$, Gallegos-Hernández $F$, Peñarroja-Flores R, Toledo-García J, Bravo JL et al. DNA damage in peripheral blood lymphocytes in patients during combined chemotherapy for breast cancer. Mutat Res 2008 Apr 2;640(12):8-15. doi: 10.1016/j.mrfmmm.2007.11.008.

13. Allione A, Pardini B, Viberti C, Oderda M, Allasia M, Gontero $P$ et al. The prognostic value of basal DNA damage level in peripheral blood lymphocytes of patients affected by bladder cancer. Urol Oncol. 2018 May;36(5):241.e15-241.e23. doi: 10.1016/j.urolonc.2018.01.006.

14. Uriol E, Sierra M, Comendador MA, J Fra, Martínez-Camblor $\mathrm{P}$, Lacave AJ et al. Long-term biomonitoring of breast cancer patients under adjuvant chemotherapy: the comet assay as a possible predictive factor. Mutagenesis $2013 \mathrm{Jan} ; 28(1): 39-48$. doi: $10.1093 /$ mutage/ges050.

15. Pupo-Balboa JB, Gutiérrez R, Pandolfi-Blanco A, CásidoRodríguez $M$, Valdés-Ramos $L$, de Armas-Santiesteban $A$. Daño basal del ADN en un grupo de individuos cubanos sanos mediante ensayo cometa. Acta Bioquím Clín Latinoam 2014; 48 (3): 367-73 http://www.scielo.org.ar/scielo.php?script=sci arttext\&pid=S0325-29572014000300010\&lng=es.

16. Collins AR. The Comet Assay for DNA Damage and Repair Principles, Applications, and Limitations Mol Biotechnol 2004 Mar;26(3):249-61. doi: 10.1385/MB:26:3:249

17. Driessens N, Versteyhe S, Ghaddhab C, Burniat, A, De Deken $\mathrm{X}$, Van Sande $\mathrm{J} \mathrm{t}$ al. Hydrogen peroxide induces DNA singleand double-strand breaks in thyroid cells and is therefore a potential mutagen for this organ. Endocr Rel Cancer. 2009 Sep;16(3): 845-56. doi: 10.1677/ERC-09-0020.

18. Kosti O, Goldman L, Saha DT, Orden RA, Pollock AJ, Madej $\mathrm{HL}$ et al. DNA damage phenotype and prostate cancer risk. Mutat Res 2011 February 3; 719(1-2): 41-46. doi: 10.1016/j. mrgentox.2010.11.005

19. Azqueta A, Slyskova J, Langie SAS, O’Neill Gaivão I and Collins A. Comet assay to measure DNA repair: approach and applications. Front. Genet 2014; 5:288. doi: 10.3389/fgene.2014.00288 
20. Chaisiriwong L, Wanitphakdeedecha R, Sitthinamsuwan P, Sampattavanich S, Chatsiricharoenkul S, Manuskiatti W et al. A Case-Control Study of Involvement of Oxidative DNA Damage and Alteration of Antioxidant Defense System in Patients with Basal Cell Carcinoma: Modulation by Tumor Removal. Oxid Med Cell Longev 2016;2016:5934024. doi: 10.1155/2016/5934024

21. Løhr M, Jensen A, Eriksen L, Grønbæk M, Loft S and Møller P. Age and metabolic risk factors associated with oxidatively damaged DNA in human peripheral blood mononuclear cells. Oncotarget 2014; 6(5):2641-26533; doi: 10.18632/oncotarget.3202

22. Garm C, Moreno-Villanueva M, Bürkle A, Petersen I, Bohr VA, Christensen $\mathrm{K}$ et al. Age and gender effects on DNA strand break repair in peripheral blood mononuclear cells. Aging Cell 2013 Feb;12(1):58-66. doi: 10.1111/acel.12019

23. Buchynska L, Brieieva O, Glushchenko N, Vorobyova L and Bilyk 0 . DNA repair deficiency in peripheral blood lymphocytes of endometrial cancer patients with a family history of cancer. BMC Cancer. 2014;14:765. doi:10.1186/1471-2407-14-765

24. Smith TR, Miller MS, Lohman KK, LD Case and Hu JJ. DNA damage and breast cancer risk Carcinogenesis. 2003;24(5):883889. doi: 10.1093/carcin/bgg037

25. Hoeijmakers JHJ. Molecular origin of cancer. DNA Damage, Aging, and Cancer. N Engl J Med. 2009 Oct 8;361(15):1475-85. doi: 10.1056/NEJMra0804615

26. Hao Luo, Zheng Li, Yi Qing, Shi-Heng Zhang, Yu Peng, Qing Li, Dong Wang. Single Nucleotide Polymorphisms of DNA Baseexcision Repair Genes (APE1, OGG1 and XRCC1) Associated with Breast Cancer Risk in a Chinese Population. Asian Pac J Cancer Prev. 2014;15(3):1133-1140 doi:10.7314/apjcp.2014.15.3.1133

27. Petkova R, Chelenkova P, Georgieva E \& Chakarov S. What's Your Poison? Impact of Individual Repair Capacity on the Outcomes of Genotoxic Therapies in Cancer. Part I-Role of Individual Repair Capacity in the Constitution of Risk for Late-Onset Multifactorial Disease, Biotechnol \& Biotechnol Eq. 2013; 27(6): 4208-4216. doi: 10.5504/BBEQ.2013.0097

28. Finch A, Beiner M, Lubinski J, Lynch HT, Moller P, Rosen B et al. Salpingo-oopherectomy and the risk of ovarian, fallopian tube, and peritoneal cancers in women with a BRCA1 or BRCA2 mutation. JAMA. 2006: 296(2): 185-92 doi: 10.1001/ jama.296.2.185;

29. Cavanagh $\mathrm{H}$ and Roger $\mathrm{KM}$. The role of BRCA1 and BRCA2 mutations in prostate, pancreatic and stomach cancers. Hered Cancer Cin Pract. 2015; 13(1):16. doi: 10.1186/s13053-0150038-x.eCollection 2015

30. Locken-Castilla A, Pacheco-Pantoja EL, Rodríguez-Brito F, MayKim Sh, López-Rivas V and Ceballos-Cruz A. Smoking index, lifestyle factors, and genomic instability assessed by single-cell gel electrophoresis: a cross-sectional study in subjects from Yucatan, Mexico. Clinical Epigenetic. 2019; 11:150 https://doi. org/10.1186/s13148-019-0745-7

31. Borrego-Soto G, Ortiz-López R and Rojas-Martínez A. lonizing radiation-induced DNA injury and damage detection in patients with breast cancer. Genet Mol Biol. 2015; 38(4): 420-432 doi: http://dx.doi.org/10.1590/S1415-475738420150019
32. Alhmoud JF, Woolley JF, Al Moustafa AE and Malki MI. DNA Damage/Repair Management in Cancers. Cancers. 2020; 12(1050): 22 p; doi:10.3390/cancers 12041050

33. Vandevoorde C, Depuydt J, Veldeman L, De Neve W, Sebastià N, Wieme G, Baert A, De Langhe S, Philippé J, Thierens H, Vral A.In vitro cellular radiosensitivity in relationship to late normal tissue reactions in breast cancer patients: a multi-endpoint case-control study. Int J Radiat Biol. 2016 Dec;92(12):823-836. Epub 2016 Oct 17. doi: 10.1080/09553002.2016.1230238

34. Khanna A. DNA Damage in Cancer Therapeutics: A Boon or a Curse? Cancer Res. 2015 Jun 1;75(11): 2133-8. doi: 10.1158/0008-5472.CAN-14-3247

35. AIRTUM Working Group. Italian cancer figures, report 2013: Multiple tumours. Epidemiol Prev 2013 Jul-Oct;37(4-5 Suppl 1):1-152

36. Gamulin M, Kopjar N, Grgić M, Ramić S, Viculin T, Petković M et al. Cytogenetic follow-up in testicular seminoma patients exposed to adjuvant radiotherapy. Coll Antropol 2010 Jun;34(2):455-65). PMID: 20698117

37. Trenner A and Sartori AA. Harnessing DNA Double-Strand Break Repair for Cancer Treatment. Front. Oncol. 2019; 9:1388. doi: $10.3389 /$ fonc. 2019.01388

38. Mallipatna A, Marino M, Singh AD. Genetics of Retinoblastoma. Asia Pac J Ophthalmol (Phila). 2016 Jul-Aug;5(4):260-4. doi: 10.1097/APO.0000000000000219.

39. Silverman BG, Lipshitz I, Keinan-Boker L. Second Primary Cancers After Primary Breast Cancer Diagnosis in Israeli Women, 1992 to 2006. J Glob Oncol 2017; 3(2): 135-142). doi: 10.1200/ JG0.2016.003699.

40. Crawford S. Anti-inflammatory/antioxidant use in long-term maintenance cancer therapy: a new therapeutic approach to disease progression and recurrence. Ther Adv Med Oncol 2014. 6(2): 52-68. doi: 10.1177/1758834014521111.

41. J. Robin Harris • Viktor I. Korolchuk, Editors. Biochemistry and Cell Biology of Ageing: Part I Biomedical \{Internet\} Science. Subcellular Biochemistry. Volume 90. Singapore. Springer. 2018. \{citado mayo 2020\}. Disponible en: https://doi. org/10.1007/978-981-13-2835-0

42. Dhir S, Tarasenko M, Napoli E and Giulivi C. Neurological, Psychiatric, and Biochemical Aspects of Thiamine Deficiency in Children and Adults. Front. Psychiatry. 2019 Apr 4;10:207. doi: $10.3389 /$ fpsyt.2019.00207

43. Sambon M, Napp A, Demelenne A, Vignisse J, Wins P, Fillet $M$ et al. Thiamine and benfotiamine protect neuroblastoma cells against paraquat and $\mathrm{B}$-amyloid toxicity by a coenzymeindependent mechanism. Heliyon. 2019 May 14;5(5): e01710. doi.org/10.1016/j.heliyon.2019.e01710

44. Suwannasom N, Kao I, Pruß A, Georgieva R and Bäumler H. Riboflavin: The Health Benefits of a Forgotten Natural Vitamin. Int. J. Mol. Sci. 2020. 21; 950. doi:10.3390/ijms21030950)

45. Fania L, Mazzanti C, Campione E, Candi E, Abeni D and Dellambra E- Role of Nicotinamide in Genomic Stability and 
Skin Cancer Chemoprevention. Int. J. Mol. Sci. 2019. 20; 5946. doi:10.3390/ijms20235946

46. Cheng SB, Lin PT, Liu HT, Peng YS, Huang SCh, and Huang YCh. Vitamin B-6 Supplementation Could Mediate Antioxidant Capacity by Reducing Plasma Homocysteine Concentration in Patients with Hepatocellular Carcinoma after Tumor Resection. BioMed Res Int. 2016;2016:7658991.doi:10.1155/ 2016/7658981

47. van de Lagemaat EE, de Groot LCPGM and van den Heuvel EGHM. Vitamin B12 in Relation to Oxidative Stress: A Systematic Review. Nutrients. 2019 Feb 25 ;11(2):482. doi:10.3390/ nu11020482

48. Doldo E, Costanza G, Agostinelli S, Tarquini Ch, Ferlosio A, Arcuri G et al. Vitamin A, Cancer Treatment and Prevention: The New Role of Cellular Retinol Binding Proteins. BioMed Res Int. 2015; 2015: 624627. doi.org/10.1155/2015/624627

49. Fabian CJ, Kimler BF and Hursting SD. Omega-3 fatty acids for breast cancer prevention and survivorship. Breast Cancer Res. 2015;17(1):62. doi 10.1186/s13058-015-0571-6

50. Greenlee H, Gammon MD, Abrahamson PE, Gaudet MM, Terry MB, Hershman DL et al. Prevalence and predictors of antioxidant supplement use during breast cancer treatment: The Long Island Breast Cancer Study Projec. Cancer 2009 Jul 15;115(14):3271-82. doi: 10.1002/cncr.24378.

51. Caldon CE. Estrogen signaling and the DNA damage response in hormone dependent breast cancers. Front Oncol 2014 May 14;4:106. doi: $10.3389 /$ fonc. 2014.00106

52. Wilson BT, Cordell HJ. Uterine carcinosarcoma/malignant mixed Müllerian tumor incidence is increased in women with breastcancer, but independent of hormone therapy. J Gynecol Oncol 2015 Oct;26(4):249-51. doi: 10.3802/jgo.2015.26.4.249

53. Wozniak K, Kolacinska A, Blasinska-Morawiec M, Morawiec-Bajda A, Morawiec Z, Zadrozny M et al. The DNA-damaging potential of tamoxifen in breast cancer and normal cells. Arch Toxicol 2007 Jul;81(7):519-27. Epub 2007 Feb 16 PMID: 17593413

54. Bazzan AJ, Newberg AB, Cho WC and Monti DA. Diet and Nutrition in Cancer Survivorship and Palliative Care. Evid Based Complement Alternat Med 2013;2013:917647. doi: $10.1155 / 2013 / 917647$

55. Ferguson LR, Chen H, Collins AR, Connell M, Damia G, Dasgupta $S$ et al. Genomic instability in human cancer: Molecular insights and opportunities for therapeutic attack and prevention through diet and nutrition. Seminars in Cancer Biology 2015; 35 S5-S24. http://dx.doi.org/10.1016/j.semcancer.2015.03.005

56. Wallace TC, Bultman S, D'Adamo Ch, Daniel CR, Debelius J, Ho E et al. Personalized Nutrition in Disrupting Cancer - Proceedings From the 2017 American College of Nutrition Annual Meeting, Journal of the American College of Nutrition. 2019. 38(1):1-14. doi: 10.1080/07315724.2018.1500499

57. Repka CP, Hayward R. Oxidative Stress and Fitness Changes in Cancer Patients after Exercise Training. Med Sci Sports Exerc 2016 Apr;48(4):607-14. doi: 10.1249/MSS.0000000000000821

58. Braam KI, van der Torre P, Takken T, Veening MA, van Dulmenden Broeder $\mathrm{E}$ et al. Physical exercise training interventions for children and young adults during and after treatment for childhood cancer. Cochrane Database Syst Rev 2016 Mar 31;3:CD008796. doi: 10.1002/14651858.CD008796.pub3 